\title{
BMJ Open Covered stents versus balloon angioplasty for failure of arteriovenous access: a systematic review and meta- analysis
}

\author{
Benjamin Ng (D) , ${ }^{1}$ Magnus Fugger, ${ }^{1}$ Igho Jovwoke Onakpoya, ${ }^{2,3}$ \\ Andrew Macdonald, ${ }^{4}$ Carl Heneghan (i) ${ }^{3}$
}

To cite: $\mathrm{Ng} \mathrm{B}$, Fugger M, Onakpoya IJ, et al. Covered stents versus balloon angioplasty for failure of arteriovenous access: a systematic review and meta-analysis. BMJ Open 2021;11:e044356. doi:10.1136/ bmjopen-2020-044356

- Prepublication history and additional supplemental material for this paper are available online. To view these files, please visit the journal online (http://dx.doi.org/10.1136/ bmjopen-2020-044356).

$\mathrm{BN}$ and MF contributed equally.

Received 31 August 2020 Accepted 27 April 2021

A) Check for updates

C Author(s) (or their employer(s)) 2021. Re-use permitted under CC BY-NC. No commercial re-use. See rights and permissions. Published by BMJ.

${ }^{1}$ Medical Sciences Division, University of Oxford, Oxford, UK ${ }^{2}$ Department of Continuing Education, University of Oxford, Oxford, UK

${ }^{3}$ Centre for Evidence-Based Medicine, University of Oxford, Oxford, UK

${ }^{4}$ Department of Radiology, Oxford University Hospitals NHS Foundation Trust, Oxford, UK

Correspondence to

Dr Benjamin Ng;

benjamin.ng1@nhs.net

\section{ABSTRACT}

Introduction Patients with end-stage renal disease may require arteriovenous (AV) access in the form of arteriovenous fistulae (AVFs) or arteriovenous grafts (AVGs) for haemodialysis. AV access dysfunction requires intervention such as plain balloon angioplasty or covered stents to regain patency.

Aim To systematically review and meta-analyse the patency outcomes of covered stents in failing haemodialysis AV access, compared with balloon angioplasty.

Methods The review was first registered on the International Prospective Register of Systematic Reviews (CRD42018069955) before data collection. We searched six electronic databases to identify relevant randomised controlled trials (RCTs) up until August 2020, without language restriction. Two reviewers assessed the suitability and quality of studies for inclusion using the Consolidated Standards of Reporting Trials guidelines. We meta-analysed data using a random-effects model. Results We included seven studies including 1147 patients in the systematic review, of which 867 had AVGs and 280 had AVFs. One study was an ongoing RCT. In the meta-analyses, we assessed patients with failing AVGs only. Overall risk of bias was moderate. Covered stents were associated with lower loss of patency versus angioplasty alone at 6, 12 and 24 months (OR 4.48, $95 \% \mathrm{Cl} 1.98$ to $10.14, \mathrm{p}<0.001 ; 0 \mathrm{R} 4.07,95 \% \mathrm{Cl} 1.74$ to 9.54, $\mathrm{p}=0.001$; OR 2.24, $95 \% \mathrm{Cl} 1.17$ to $4.29, \mathrm{p}=0.01$, respectively). Covered stents afforded superior access circuit primary patency compared with angioplasty alone at 6 and 12 months $(0 \mathrm{R} 1.91,95 \% \mathrm{Cl} 1.31$ to 2.80, $\mathrm{p}<0.001$; OR 1.97, $95 \% \mathrm{Cl} 1.14$ to $3.41, \mathrm{p}=0.02$, respectively). This was not significant at 24 months. There was no significant difference in loss of secondary patency between groups at 12 or 24 months $(0 \mathrm{R} 0.74,95 \% \mathrm{Cl} 0.45$ to $1.23, p=0.25$; OR $0.67,95 \% \mathrm{Cl} 0.29$ to $0.154, p=0.34$, respectively).

Conclusion Our results support use of covered stents over angioplasty alone, at 6,12 and 24 months in failing AVGs. Further clinical trials are warranted.

\section{INTRODUCTION}

End-stage renal disease (ESRD) is a chronic debilitating condition that is rising in
Strengths and limitations of this study

- This study provides the most up-to-date systematic review of prospective studies of the outcomes of covered stents versus angioplasty in failing arteriovenous (AV) access.

- A random-effects model was employed to account for heterogeneity among different studies.

- This meta-analysis included primary patency at 24 months and access circuit primary patency outcomes.

- Due to lack of data on covered stents in failing AV fistulae, our pooled analysis only focused on failing AV grafts.

- Due to lack of data on cephalic arch stenoses, metaanalysis of patients with these particular stenoses were not performed.

incidence $^{1}$ and may be treated with kidney transplant. Transplant, however, is not always possible due to the limited supply of donor kidneys and contraindications to surgery in potential recipients. As a consequence, over two million patients worldwide with ESRD are currently undergoing haemodialysis, a form of renal replacement therapy. ${ }^{2}$

Haemodialysis requires an access site either by creating autogenous arteriovenous fistulae $(\mathrm{AVFs})$ or via arteriovenous grafts $(\mathrm{AVGs})^{3}$; however, stenoses of these circuits inevitably occur over time. Excluding the cephalic arch, these are initially managed by plain balloon angioplasty, which provides a mechanical force to reopen the lumen of the circuit. However, when these stenoses become recurrent, angioplasty may be inadequate for maintaining patency. In situ covered stents (also known as stent grafts) are increasingly employed to provide a sustained mechanical force to maintain patency of arteriovenous (AV) access circuits when primary angioplasty has failed. Nevertheless, introduction of any 
foreign devices into blood vessels introduces risk of infections and other specific complications, including thrombosis, stent migration and stent fracture.

Haemodialysis is very common worldwide, and the intervention of choice in maintaining patency of circuits could have stark implications on quality of life and risk to patients, in addition to significant health service costs. ${ }^{4}$ There are currently two published systematic reviews comparing the outcomes of angioplasty versus stents for recurrent stenosis in AV circuits. ${ }^{56}$ However, the studies included bare-metal stents and were incomplete as a recent randomised controlled trial (RCT) comparing the two interventions was not included. Moreover, none of these studies included results pertaining to AVFs.

Therefore, the objective of this systematic review was to assess the effectiveness of covered stents versus plain balloon angioplasty in both AVGs and AVFs.

\section{METHODS}

\section{Literature search}

In accordance with guidelines, our systematic review protocol was registered with the International Prospective Register of Systematic Reviews on January 2018 (CRD42018069955). We searched six databases for relevant studies (CENTRAL, DARE, MEDLINE, Embase, SCIEXPANDED and CPCI-S) without language restriction from inception until May 2018. Existing trials were also searched, and intermediate results were also considered. Search terms are specified in online supplemental file 1. The searches were updated in August 2020.

\section{Selection criteria}

We included only RCTs in adults ( $\geq 18$ years) comparing covered stents versus balloon angioplasty and patients undergoing haemodialysis with recurrent stenosis of $\mathrm{AV}$ access. We excluded trials where patients had definitive treatment for renal failure; or other interventions such as drug-eluting stents or bare-metal stents. Two reviewers (BN and MF) independently screened potential studies for inclusion. Any disagreements were resolved by two senior authors (IJO and $\mathrm{CH}$ ).

\section{Risk of bias assessment}

Two reviewers (BN and $\mathrm{MG}$ ) independently assessed the risk of bias of included published studies. Each item was judged as being at high, low or unclear risk of bias as set out in the criteria adapted from the Consolidated Standards of Reporting Trials guidelines. ${ }^{78}$ Disagreements were resolved via consensus.

\section{Data extraction}

Two reviewers (BN and MF) independently extracted the following data from each included study: (1) number of participants, (2) age, (3) gender, (4) percentage stenosis of access site, (5) length of stenosis, (6) comorbidities, (7) type of access circuit (AVG or AVF), (8) age of access circuit, (9) technical success, (10) primary patency, (11) secondary patency, (12) number of interventions before failure and (13) stent types. Disagreements were resolved via consensus.

\section{Data analysis}

To calculate pooled mean for study characteristics, mean values provided in each study were multiplied by their sample sizes. These were summed and subsequently divided by the total sample size. Pooled SD was determined by Cohen's SD formula. ${ }^{9}$ We used Review Manager V.5. $4^{10}$ for the meta-analyses and used a Mantel-Haenszel random-effects model ( $\mathrm{BN}$ and $\mathrm{MF}$ ) as patient characteristics were quite heterogenous (table 1). ${ }^{10}$ We used ORs with $95 \%$ CIs to compare event rates. We assessed heterogeneity using the $\mathrm{I}^{2}$ statistic; values of $25 \%, 50 \%$ and $75 \%$ represented mild, moderate and substantial heterogeneity, respectively.

\section{Patient and public involvement statement \\ Patients or the public was not involved.}

\section{RESULTS}

Our search strategy produced 1672 articles, of which 14 records were considered eligible (figure 1 and online supplemental file 1). Seven further studies were excluded as they analysed bare-metal stents rather than covered ones. One other study, which was initially excluded, was added later due to its significance. In total, in all eight relevant studies (all RCTs), we included 867 patients for meta-analysis, who all had AVGs. ${ }^{11-18}$ The patient populations of the two results were overlapping. ${ }^{15} 17$ All studies were RCTs (four multicentre and two single-centre trials). Excluded studies from the meta-analyses were one small trial on cephalic arch stenosis and an ongoing trial (total of 294 patients), both of which had a patient population with AVFs. ${ }^{12} 18$ The key details of these papers are summarised in table 1.

Of these 867 patients, $432(49.8 \%)$ were treated by balloon angioplasty alone, and $435(50.2 \%)$ were treated by covered stents (table 1 ). The mean ages were $61.7 \pm 14.0$ (39.4\% men) for the angioplasty group and $63.2 \pm 13.2$ (36.8\% men) for the covered stent group. All studies but one reported hypertension and diabetes as comorbidities; two studies had overlapping patient populations. In the angioplasty group, $57.0 \%(171 / 300)$ had diabetes and $86.7 \%(260 / 300)$ had hypertension. For covered stenting, $56.9 \%(169 / 297)$ of the patient population had diabetes and $91.9 \%(273 / 297)$ had hypertension.

The average duration of access circuit (four studies) for angioplasty was $2.20 \pm 2.34$ years and that for covered stenting was $2.40 \pm 2.73$ years $(\mathrm{p}<0.001)$. One small study was excluded as it only reported this parameter in median and $\mathrm{IQR}$ ranges.

The pooled mean percentage stenosis was $71.6 \% \pm 12.3 \%$ in the angioplasty group compared with $70.4 \% \pm 11.7 \%$ in the covered stent group (five studies, $\mathrm{p}=0.04$ ). The length 


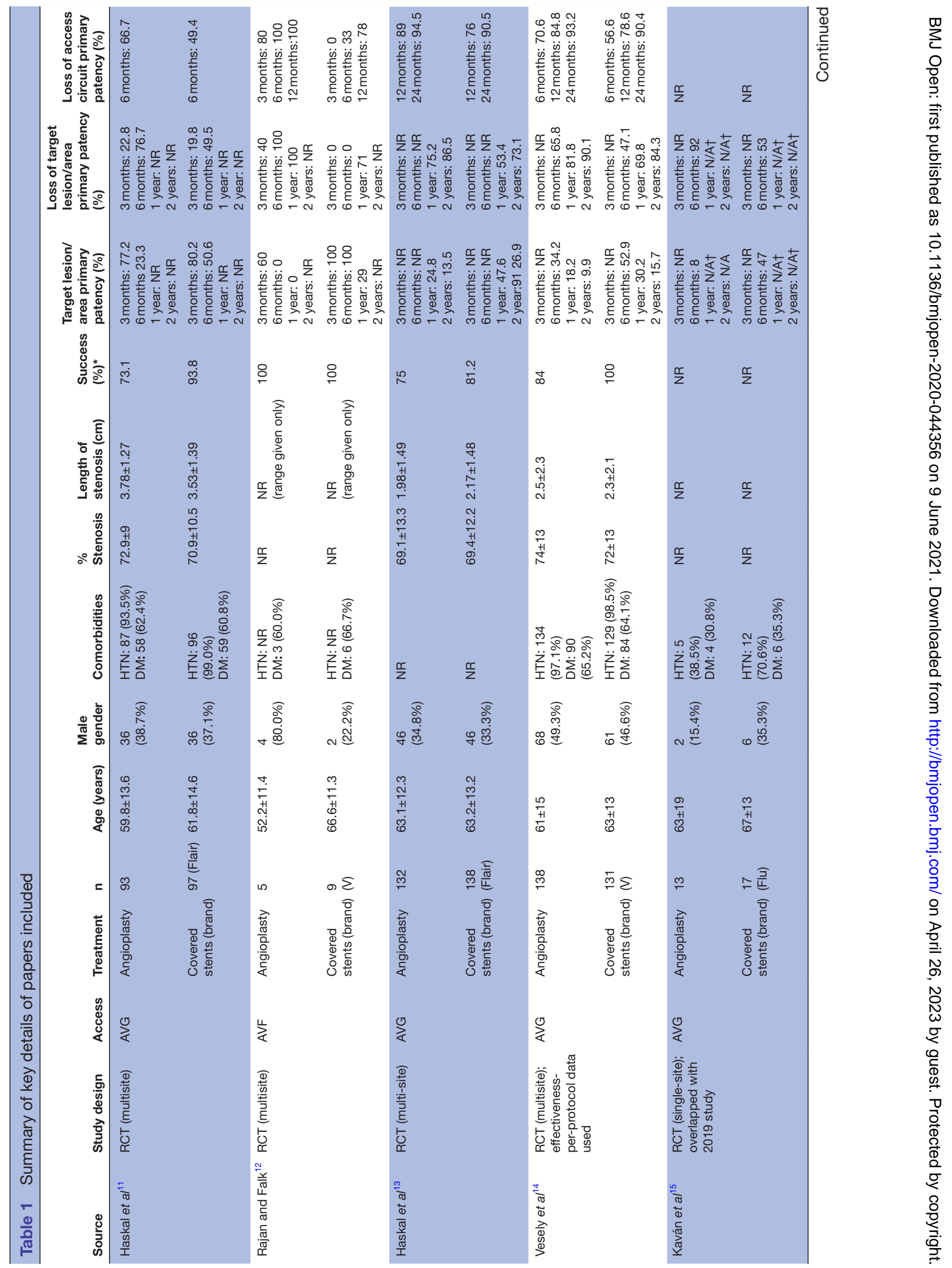




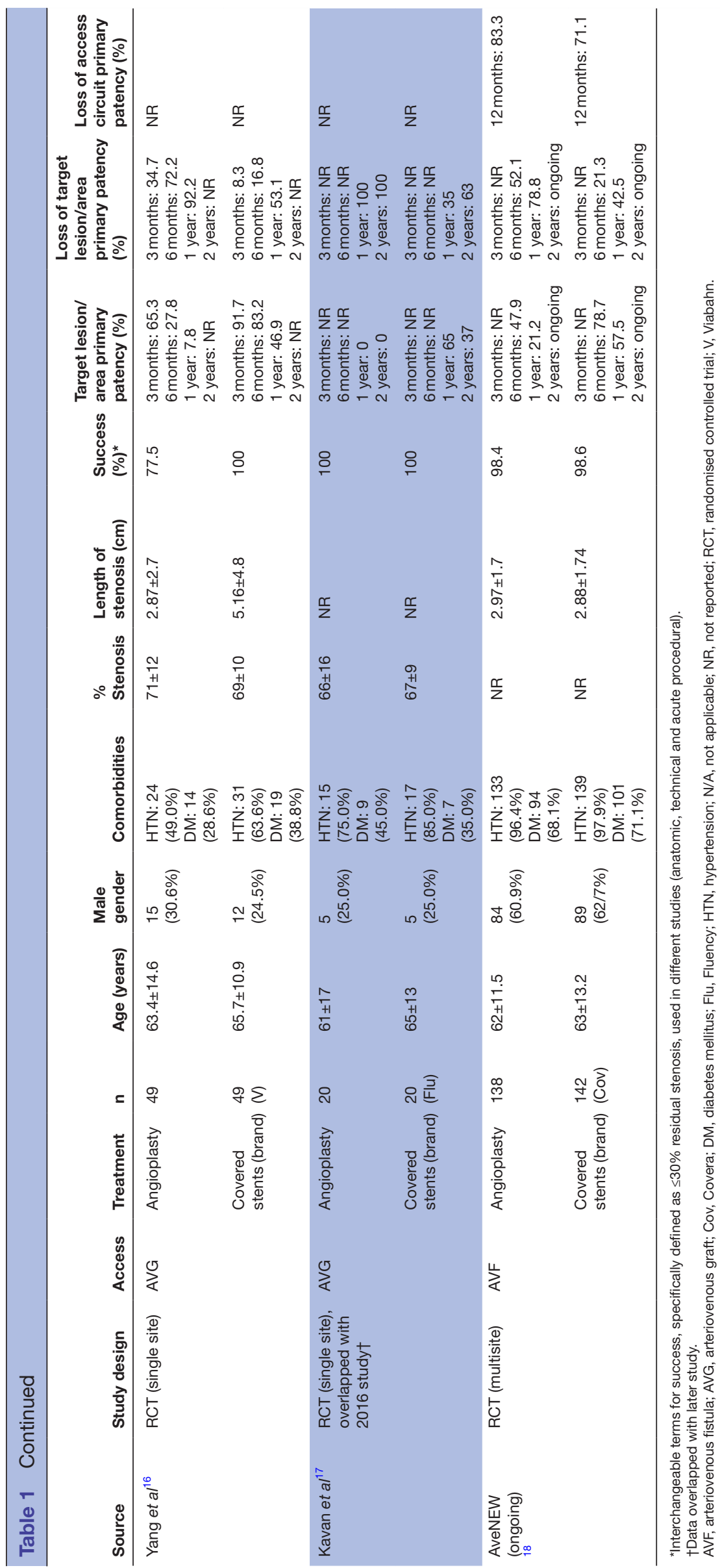

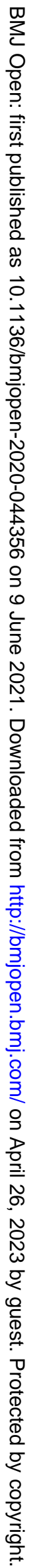




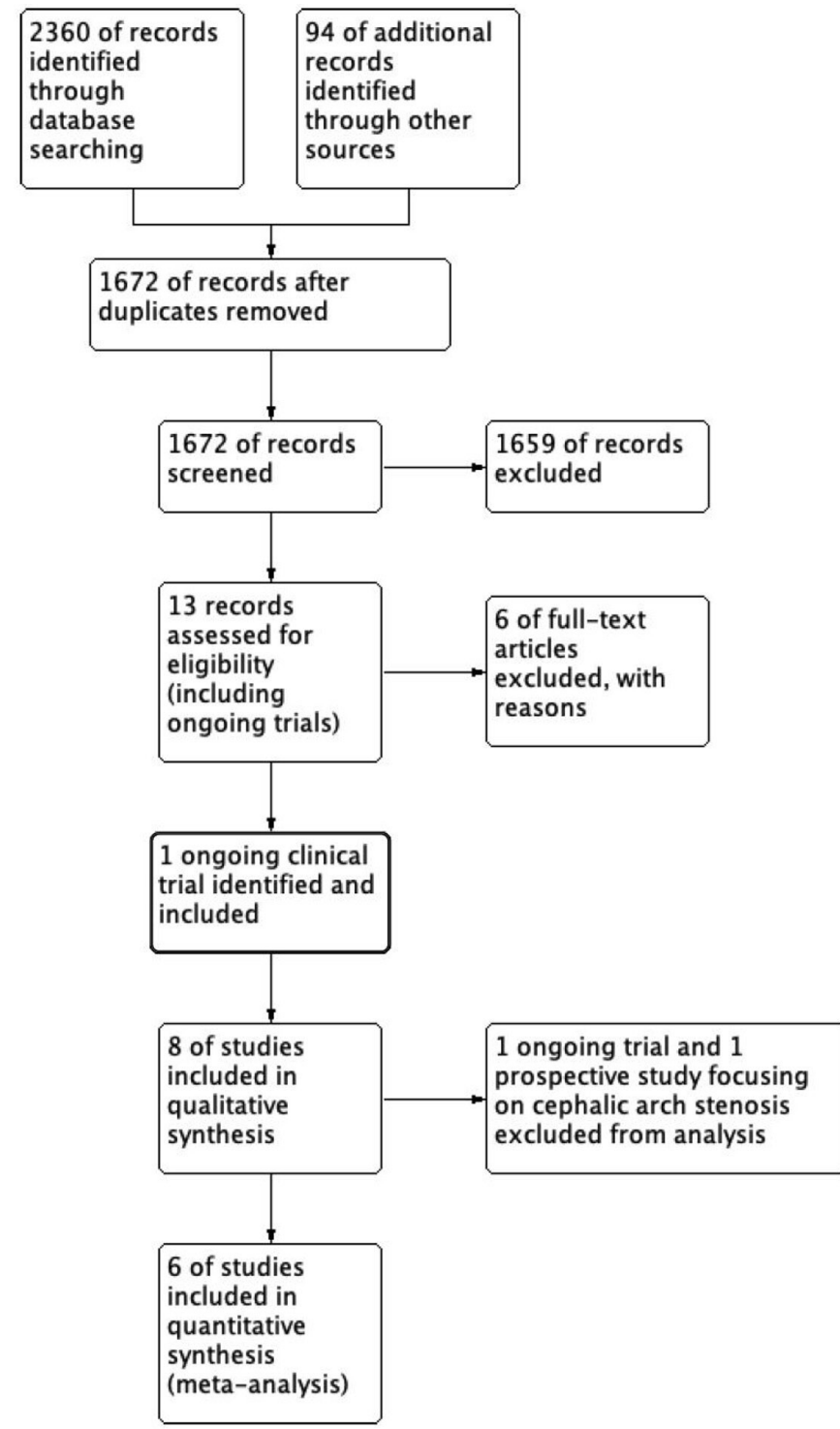

Figure 1 Preferred Reporting Items for Systematic Reviews and Meta-Analyses study flow diagram.

of stenosis was $2.7 \pm 2.1 \mathrm{~cm}$ for angioplasty compared with $2.9 \pm 2.0 \mathrm{~cm}$ for covered stent (four studies, $\mathrm{p}<0.001$ ).

The angioplasty group had a mean of $1.7( \pm 2.4)$ previous interventions before failure compared with the covered stent group (1.8 \pm 2.2$)$ (two studies, $\mathrm{p}<0.001)$.

The mean technical or anatomical success (defined as residual stenosis $\leq 30 \%$ after intervention) in the angioplasty group was $84.7 \%$ and that in the covered stent group (six studies) was $95.6 \%$. The covered stent brands used (when stated) were $40.7 \% \quad(n=235)$ Flair stents, $31.2 \% \quad(\mathrm{n}=180)$ Viabahn, $24.6 \% \quad(\mathrm{n}=142)$ Covera and $3.5 \%(n=20)$ Fluency.

Other important parameters are summarised in online supplemental tables 1-4.

\section{Risk of bias assessment}

Figure 2 shows the risk of bias assessment of the seven studies. There was no mention of allocation concealment in two out of the seven prospective studies. ${ }^{15} 17$ Blinding of participants and personnel was not possible, and we therefore allocated this as high risk of bias. We did not identify any detection or attrition bias in any prospective studies. Only one prospective study was judged to have reporting bias, where a 2-month primary patency was reported instead of the standard 1 month, ${ }^{11}$ but we note this was the first preliminary study of its kind. In all but one prospective study, there were conflicts of interest in terms of study funding by device manufacturers. The overall risk of bias across the studies was judged to be moderate.

\section{Loss of primary patency in failing AVGs}

The target lesion or target area primary patency is the Kaplan-Meier estimated time interval of patency of the target lesion or area from initial intervention to next access intervention or access thrombosis. In other words, primary patency ended when only the target lesion or area recurred.

At 6 months, loss of primary patency was significantly lower in patients who had covered stents compared with angioplasty alone (OR 4.48, 95\% CI 1.98 to $10.14, \mathrm{p}<0.001, \mathrm{I}^{2}=74 \%$; figure $3 \mathrm{~A}$ ). At 12 months, this outcome was also significantly lower in the covered stent group (OR 4.07, 95\% CI 1.74 to 9.54, p=0.001, $\mathrm{I}^{2}=73 \%$; figure $\left.3 \mathrm{~B}\right)$. The results similarly favoured covered stents at 24 months (OR 2.24, 95\% CI 1.17 to $4.29, \mathrm{p}=0.01, \mathrm{I}^{2}=34 \%$; figure $3 \mathrm{C}$ ).

\section{Loss of access circuit primary patency (ACPP) in failing AVGs}

The ACPP is the time estimate from initial study intervention to next access intervention or access thrombosis, derived from the Kaplan-Meier curve. In other words, ACPP ended when any stenoses were detected (not just the target lesion or area).

Only two studies $(\mathrm{n}=539)$ included outcomes on ACPP at 6, 12 and 24 months. Meta-analysis (figure 4) showed that covered stents were significantly better in terms of loss of ACPP than percutaneous angioplasty at 6 months (OR 1.91, 95\% CI 1.31 to $2.80, \mathrm{p}<0.001, \mathrm{I}^{2}=0 \%$ ) and 12 months (OR 1.97, $95 \%$ CI 1.14 to $\left.3.41, \mathrm{p}=0.02, \mathrm{I}^{2}=29 \%\right)$. This was nonsignificant at 24 months (OR $1.70,95 \%$ CI 0.89 to $\left.3.26, \mathrm{p}=0.11, \mathrm{I}^{2}=0\right)$.

\section{Loss of secondary patency in failing AVGs}

The access circuit secondary patency refers to the time interval estimate from the Kaplan-Meier curve from initial study intervention to abandonment of the access circuit. Only two studies $(\mathrm{n}=300)$ included secondary patency at 12 and 24 months as a measure of outcome. Meta-analysis (figure 5) showed nonsignificant results in terms of loss of secondary patency at 12 months (OR $0.74,95 \%$ CI 0.45 to $1.23, \mathrm{p}=0.25$, $\mathrm{I}^{2}=0 \%$ ) and at 24 months (OR $0.67,95 \%$ CI 0.29 to $0.154, \mathrm{p}=0.34, \mathrm{I}^{2}=17 \%$ ). 


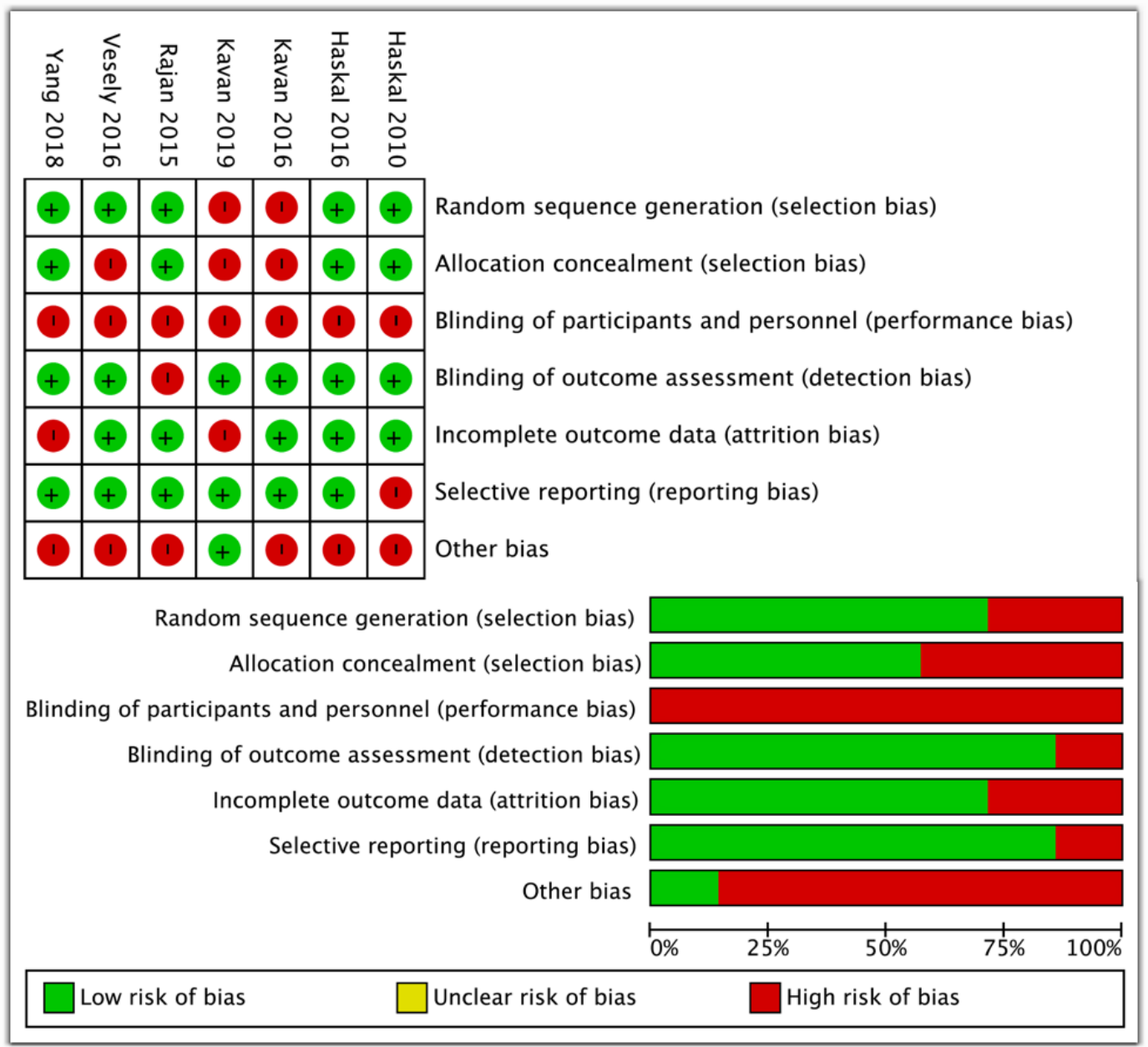

Figure 2 Risk of bias assessment. (A) Risk of bias summary: review authors' judgements about each risk of bias item for each included study. (B) Risk of bias graph: review authors' judgements about each risk of bias item presented as percentages across all included studies.

\section{DISCUSSION}

\section{Summary of main findings}

Our meta-analysis showed covered stent placement in AVGs was significantly superior to angioplasty in terms of loss of primary patency at 6,12 and 24 months. Furthermore, we found that covered stents also had significantly lower loss of ACPP than angioplasty at 6 and 12 months, but this was non-significant at 24 months. There were non-significant differences in loss of secondary patency. The meta-analysis findings should be interpreted with caution because of significant heterogeneity observed in some of the results. The substantial heterogeneity observed in some of the meta-analysis is likely due to variation in sample sizes and methodology (largely selection biases) across the included studies.

\section{Comparison with the existing literature}

Previously, two similar meta-analyses have been performed comparing covered stent deployment and percutaneous transluminal angioplasty. ${ }^{5}{ }^{6}$ We build on the works of these two studies by extending our search and including two new completed RCTs (one new and one updated) in our analyses. Moreover, our inclusion of only covered stents rather than bare-metal stents better reflects clinical practice as the efficacy of bare-metal stents for this indication has been shown to be inferior due to development of in-stent stenoses. ${ }^{19}{ }^{20}$ The discrepancies in the pooled analysis between our results and the two other publications may be due to the different studies included in each meta-analysis. Furthermore, one group used an inverse variance fixed-effects model to calculate HRs. ${ }^{6}$ Nevertheless, both studies and our results clearly favoured covered stents over angioplasty in terms of primary patency.

\section{Strengths and limitations}

We searched extensively to identify relevant studies and accounted for the reporting quality of included studies. Our systematic review summarised the results of covered stents with balloon angioplasty in both failing AVGs as well as AVFs.

However, we recognise several limitations. First, we may not have identified all the relevant studies, especially unpublished studies. Second, the heterogeneity of technical definitions (online supplemental table 1) 


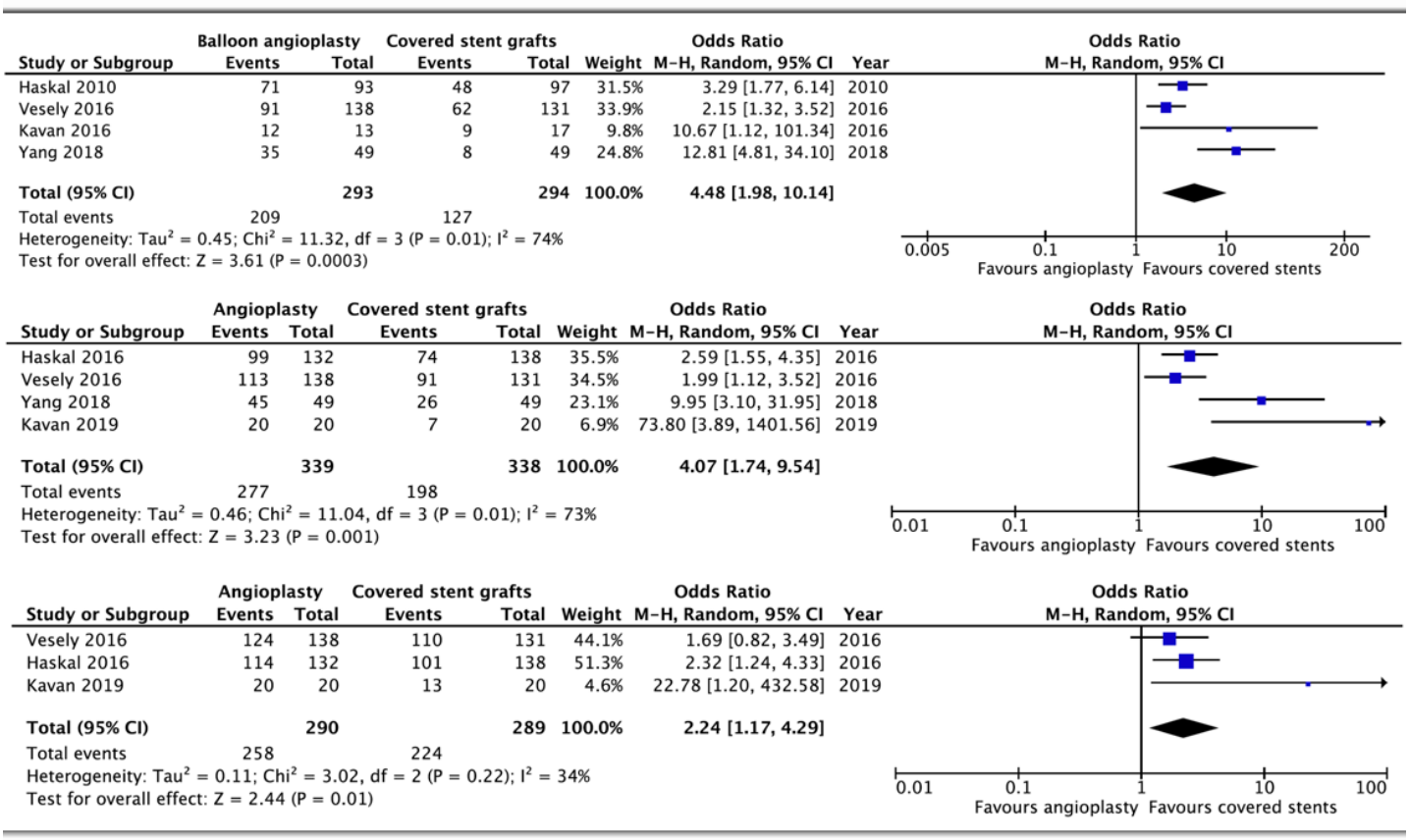

Figure 4 Forest plot of comparison of the effect of percutaneous balloon angioplasty versus covered stent grafts on loss of access circuit primary patency at (A) 6, (B) 12 and (C) 24 months using a random-effects model. M-H, Mantel-Haenszel. 


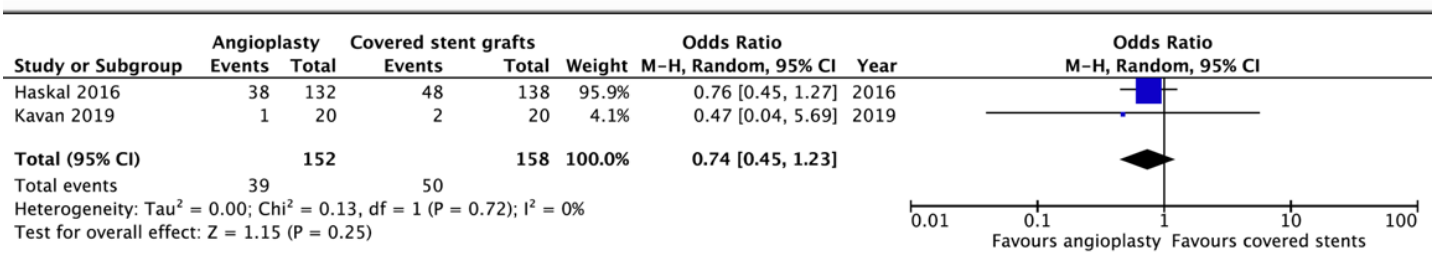

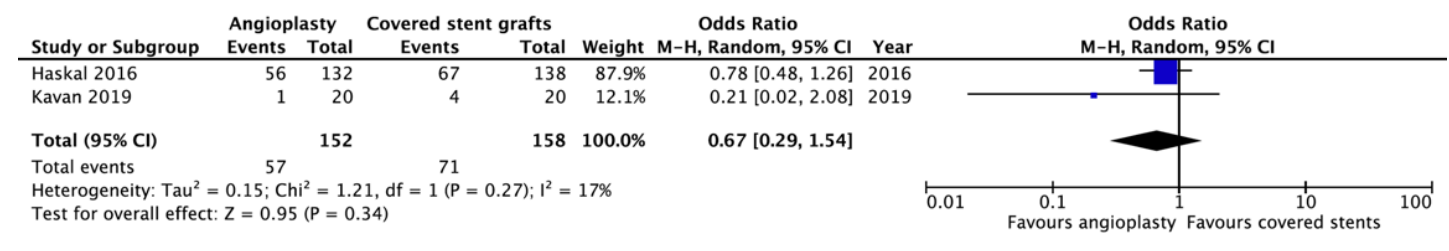

Figure 5 Forest plot of comparison of the effect of percutaneous balloon angioplasty versus covered stent on loss of secondary patency at (A) 12 and (B) 24 months using a random-effects model. M-H, Mantel-Haenszel.

patency invasive evaluation and patency loss definitions, making it more rigorous than the other trials. Admittedly, while difficult to do so, further trials with better quality should be conducted to allow for more robust assessments.

Cephalic arch stenosis is a common lesion which is notoriously difficult to treat with angioplasty alone compared with other types of stenoses found in AVFs. ${ }^{22}{ }^{23}$ Mechanical factors such as high flow rates in brachiocephalic fistulae and anatomical factors, for example, rigidity of surrounding structures, predispose intimal hyperplasia and subsequently stenosis and thrombosis. ${ }^{22}{ }^{24}$ In this systematic review, the stenoses for almost all included studies fall outside the cephalic arch as they are all focused on AVGs (table 1 and online supplemental table 2). Only the ongoing AveNew trial and one small, randomised trial focused on AVFs and cephalic arch stenoses. ${ }^{12}{ }^{18}$ Due to the limited endovascular studies examining covered stents on this specific lesion, we were unable to perform any meaningful meta-analysis on it. Further research is required on their clinical significance which would come in the form of the promising ongoing AveNew trial. ${ }^{18}$

Other than the superior clinical benefits conferred by covered stents compared with angioplasty alone in dysfunctional AV access, there might be additional economic benefits to the usage of covered stents. Two recent health economic analyses suggested that in a private healthcare setting such as the USA, both the payer and service provider might benefit from covered stent deployment in the long run. ${ }^{25}{ }^{26}$ From payer and patient perspectives, this is due to fewer reinterventions compared with percutaneous transluminal angioplasty alone, while from a service provider point of view, there were cost savings from the lower rates of reinterventions. While there are no current health economic analyses on the cost-benefits of covered stents in a public healthcare model, for example, the National Health Service in the UK, the cost savings could arguably still be extrapolated and applicable.
Finally, we are aware of the potential of drug-eluting or drug-coated devices (stents or balloons) in dysfunctional AV access. There are conflicting results in the current literature regarding patency benefit of drug-coated balloon versus normal angioplasty, ${ }^{27-29}$ and further research is needed to compare these devices with current interventions.

\section{CONCLUSION}

Loss of primary patency at 6,12 and 24 months favoured the use of covered stents compared with percutaneous transluminal angioplasty alone, in failing AVGs. Insufficient studies were available for failing AVFs to make the same comparison. Further clinical trials are warranted.

Acknowledgements We thank Nia Roberts for helping with the initial and updated literature searches.

Contributors $\mathrm{BN}$ and MF contributed equally to this paper and performed data collection and data analysis. BN and AM conceived the study. BN and IJO wrote the PROPSERO protocol and performed the literature search and screening of appropriate studies. BN, MF and AM drafted the initial paper, while IJO and $\mathrm{CH}$ provided critical revision of the manuscript.

Funding The authors have not declared a specific grant for this research from any funding agency in the public, commercial or not-for-profit sectors.

Competing interests None declared.

Patient and public involvement statement Patients or the public was not involved.

Patient consent for publication Not required.

Ethics approval No ethics approval was required for this study.

Provenance and peer review Not commissioned; externally peer reviewed.

Data availability statement Data are available upon reasonable request. All data relevant to the study are included in the article or uploaded as supplementary information. Our protocol is published on International Prospective Register of Systematic Reviews (CRD42018069955). Our search strategy is available as a supplementary document. Full analysis data on Review Manager are available from the corresponding author (benjamin.ng1@nhs.net).

Supplemental material This content has been supplied by the author(s). It has not been vetted by BMJ Publishing Group Limited (BMJ) and may not have been peer-reviewed. Any opinions or recommendations discussed are solely those of the author(s) and are not endorsed by BMJ. BMJ disclaims all liability and 
responsibility arising from any reliance placed on the content. Where the content includes any translated material, BMJ does not warrant the accuracy and reliability of the translations (including but not limited to local regulations, clinical guidelines, terminology, drug names and drug dosages), and is not responsible for any error and/or omissions arising from translation and adaptation or otherwise.

Open access This is an open access article distributed in accordance with the Creative Commons Attribution Non Commercial (CC BY-NC 4.0) license, which permits others to distribute, remix, adapt, build upon this work non-commercially, and license their derivative works on different terms, provided the original work is properly cited, appropriate credit is given, any changes made indicated, and the use is non-commercial. See: http://creativecommons.org/licenses/by-nc/4.0/.

\section{ORCID iDs}

Benjamin Ng http://orcid.org/0000-0003-4296-2948

Carl Heneghan http://orcid.org/0000-0002-1009-1992

\section{REFERENCES}

1 Gilg J, Caskey F, Fogarty D. Uk renal registry 18th annual report: chapter 1 UK renal replacement therapy incidence in 2014: national and Centre-specific analyses. Nephron 2016;132 Suppl 1:9-40.

2 Liyanage T, Ninomiya T, Jha V, et al. Worldwide access to treatment for end-stage kidney disease: a systematic review. Lancet 2015;385:1975-82.

3 Kerlan RK, LaBerge JM. Fistula first, stent graft second. N Engl J Med 2010;362:550-2.

4 MacNeill SJ, Ford D. Uk renal registry 19th annual report: chapter 2 UK renal replacement therapy prevalence in 2015: national and centre-specific analyses. Nephron 2017;137 Suppl 1:45-72.

5 Kouvelos GN, Spanos K, Antoniou GA, et al. Balloon angioplasty versus stenting for the treatment of failing arteriovenous grafts: a meta-analysis. Eur J Vasc Endovasc Surg 2018;55:249-56.

$6 \mathrm{Hu} \mathrm{H}, \mathrm{Wu}$ Z, Zhao J, et al. Stent graft placement versus angioplasty for hemodialysis access failure: a meta-analysis. J Surg Res 2018;226:82-8.

7 Moher D, Schulz KF, Altman DG. The CONSORT statement: revised recommendations for improving the quality of reports of parallelgroup randomised trials. Lancet 2001;357:1191-4.

8 Altman DG, Schulz KF, Moher D, et al. The revised consort statement for reporting randomized trials: explanation and elaboration. Ann Intern Med 2001;134:663.

9 Cohen J. Statistical power analysis for the behavioral sciences. 2nd ed. Hillsdale: Lawrence Erlbaum, 1988.

10 The Nordic Cochrane Centre, The Cochrane Colloboration. Review manager (RevMan) [Computer Program], version 5.4. London: The Cochrane Colloboration, 2020.

11 Haskal ZJ, Trerotola S, Dolmatch B, et al. Stent graft versus balloon angioplasty for failing dialysis-access grafts. $N$ Engl J Med 2010;362:494-503.

12 Rajan DK, Falk A. A randomized prospective study comparing outcomes of angioplasty versus VIABAHN stent-graft placement for cephalic arch stenosis in dysfunctional hemodialysis accesses. $J$ Vasc Interv Radiol 2015;26:1355-61.
13 Haskal ZJ, Saad TF, Hoggard JG, et al. Prospective, randomized, Concurrently-Controlled study of a stent graft versus balloon angioplasty for treatment of arteriovenous access graft stenosis: 2-year results of the RENOVA study. J Vasc Interv Radiol 2016;27:1105-14.

14 Vesely T, DaVanzo W, Behrend T, et al. Balloon angioplasty versus Viabahn stent graft for treatment of failing or thrombosed prosthetic hemodialysis grafts. J Vasc Surg 2016;64:1400-10.

15 Kaván J, Křivánek J, Forejtová L, et al. Comparison of one-year patency rate and cost-effectiveness of stent graft vs. stent vs. PTA in dialysis AV graft. Ces Radiol 2016;70:78-84.

16 Yang H-T, Yu S-Y, Su T-W, et al. A prospective randomized study of stent graft placement after balloon angioplasty versus balloon angioplasty alone for the treatment of hemodialysis patients with prosthetic graft outflow stenosis. J Vasc Surg 2018;68:546-53.

17 Kavan J, Kudlicka J, Malik J, et al. Treatment of failing arterio-venous dialysis graft by angioplasty, stent, and stent graft: Two-years analysis of patency rates and cost-effectiveness. Exp Ther Med 2019;18:4144.

18 Dolmatch B. AVeNEW trial: 12-month update. in: Leipzig international course, 2020

19 Kim CY, Tandberg DJ, Rosenberg MD, et al. Outcomes of prosthetic hemodialysis grafts after deployment of bare metal versus covered stents at the venous anastomosis. Cardiovasc Intervent Radiol 2012;35:832-8.

20 Karnabatidis D, Kitrou P, Spiliopoulos S, et al. Stent-Grafts versus angioplasty and/or bare metal stents for failing arteriovenous grafts: a cross-over longitudinal study. J Nephrol 2013;26:389-95.

21 Salman L, Asif A. Stent graft for nephrologists: concerns and consensus. Clin J Am Soc Nephrol 2010;5:1347-52.

22 Rajan DK, Bunston S, Misra S, et al. Dysfunctional autogenous hemodialysis fistulas: outcomes after angioplasty--are there clinical predictors of patency? Radiology 2004;232:508-15.

23 Hammes M, Funaki B, Coe FL. Cephalic arch stenosis in patients with fistula access for hemodialysis: relationship to diabetes and thrombosis. Hemodial Int 2008;12:85-9.

24 Boghosian M, Cassel K, Hammes M, et al. Hemodynamics in the cephalic arch of a brachiocephalic fistula. Med Eng Phys 2014;36:822-30.

25 Dolmatch B, Hogan A, Ferko N. An economic analysis of stent grafts for treatment of vascular access stenosis: point-of-care and Medicare perspectives in the United States. J Vasc Interv Radiol 2018;29:765-73.

26 Mohr BA, Sheen AL, Roy-Chaudhury P, et al. Clinical and economic benefits of stent grafts in dysfunctional and thrombosed hemodialysis access graft circuits in the revise randomized trial. $J$ Vasc Interv Radiol 2019;30:203-11.

27 Kennedy SA, Mafeld S, Baerlocher MO, et al. Drug-Coated balloon angioplasty in hemodialysis circuits: a systematic review and metaanalysis. J Vasc Interv Radiol 2019;30:483-94.

28 Yan Wee IJ, Yap HY, Tang TY, et al. A systematic review, metaanalysis, and meta-regression of the efficacy and safety of endovascular arteriovenous fistula creation. J Vasc Surg 2020;71:309-17

29 Liao M-T, Chen M-K, Hsieh M-Y, et al. Drug-coated balloon versus conventional balloon angioplasty of hemodialysis arteriovenous fistula or graft: a systematic review and meta-analysis of randomized controlled trials. PLoS One 2020;15:e0231463. 